\title{
Thermal, Spectroscopic and Chromatographic Characterization of Biofield Energy Treated Benzophenone
}

\author{
Mahendra Kumar Trivedi ${ }^{1}$, Alice Branton ${ }^{1}$, Dahryn Trivedi ${ }^{1}$, Gopal Nayak ${ }^{1}$, Gunin Saikia ${ }^{2}$, \\ Snehasis Jana ${ }^{2, *}$ \\ ${ }^{1}$ Trivedi Global Inc., Henderson, NV, USA \\ ${ }^{2}$ Trivedi Science Research Laboratory Pvt. Ltd., Bhopal, Madhya Pradesh, India
}

Email address:

publication@trivedisrl.com (S. Jana)

\section{To cite this article:}

Mahendra Kumar Trivedi, Alice Branton, Dahryn Trivedi, Gopal Nayak, Gunin Saikia, Snehasis Jana. Thermal, Spectroscopic and Chromatographic Characterization of Biofield Energy Treated Benzophenone. Science Journal of Analytical Chemistry.

Vol. 3, No. 6, 2015, pp. 109-114. doi: 10.11648/j.sjac.20150306.15

\begin{abstract}
The aim of the present study was to evaluate the impact of biofield energy treatment on the thermal, spectroscopic, and chemical properties of benzophenone. The study was done using various analytical methods such as gas chromatography-mass spectrometry (GC-MS), high performance liquid chromatography (HPLC), differential scanning calorimetry (DSC), Fourier transform infrared (FT-IR) spectroscopy, and ultraviolet-visible (UV-Vis) spectroscopy. The benzophenone sample was divided into two parts, one part was subjected to Mr. Trivedi's biofield energy treatment, called as treated and the other part was remained as untreated, called as control. Mass spectra showed the molecular ion peak at $m / z=182$ in control and all the treated benzophenone samples with different intensities (treated samples further divided in to three parts, $\mathrm{T} 1$, T2, and T3 for GC-MS study). The isotopic abundance ratio of ${ }^{2} \mathrm{H} /{ }^{1} \mathrm{H},{ }^{13} \mathrm{C} /{ }^{12} \mathrm{C}(\mathrm{PM}+1) / \mathrm{PM}$ and in treated sample was decreased by $44.87 \%$ in $\mathrm{T} 2$ and slightly increased upto $5.79 \%$ in case of $\mathrm{T} 1$ as compared to the control [where, PM- primary molecule, $(\mathrm{PM}+1)$ - isotopic molecule either for ${ }^{13} \mathrm{C}$ or $\left.{ }^{2} \mathrm{H}\right]$. Moreover, isotopic abundance ratio of ${ }^{18} \mathrm{O} /{ }^{16} \mathrm{O}(\mathrm{PM}+2) / \mathrm{PM}$ in the treated sample was increased up to $22.64 \%$ in T3. The retention time of treated benzophenone was slightly increased $(0.88 \mathrm{~min})$ as compared to the control in HPLC chromatogram. The DSC data exhibited that the heat of degradation of treated benzophenone was increased by $674.16 \%$ as compared to the control. While, $\mathrm{C}=\mathrm{O}$ stretching frequency of treated sample was shifted by $6 \mathrm{~cm}^{-1}$ to low energy region in FT-IR spectroscopy. Further, the UV-Vis spectra of control sample showed characteristic absorption peaks at $210 \mathrm{~nm}$ and $257 \mathrm{~nm}$ that was blue shifted to $205 \mathrm{~nm}$ and $252 \mathrm{~nm}$, respectively in the treated sample. These results suggested that biofield treatment has significantly altered the thermal, spectroscopic, and chemical properties of benzophenone, which could make them more useful as reaction intermediate in industrial applications.
\end{abstract}

Keywords: Biofield Energy Treatment, Benzophenone, Gas Chromatography-Mass Spectrometry, High Performance Liquid Chromatography

\section{Introduction}

Benzophenone is an aromatic ketone, generally used in cosmetic products as ultraviolet (UV) absorber however it is suspected of causing cancer and toxic to aquatic life with long-term effects [1]. The UV absorption arises from the conjugation of the electrons between the two benzene rings and the carbonyl $\mathrm{C}=\mathrm{O}$ group (Figure 1) [2].

The chemicals that absorb UV radiation in the range of 280-400 $\mathrm{nm}$ are called UV filter molecules. These chemicals are added to sunscreen products such as lipsticks, lotions, fragrances, skin lotions, hair sprays and shampoos in concentration upto $10 \%$ [3]. Apart from their advantageous properties, some UV-filters interfere with the endocrine system of mammals leading to adverse effects on reproduction and development [4]. Moreover, benzophenone can be used as a photo initiator in UV-curing applications [5], this can also be used as UV filter in plastic packaging material to prevent photo-degradation of the packaged content. The use of benzophenone allows manufacturers to package the products in clear glass or plastic without which, opaque or dark packaging would be required [6]. Further, the insecticidal activities of benzophenone hydrazones were first described by researchers at DuPont in 1973. Subsequently, 
Copping and coworkers reported type I substituted hydrazones for the first time, which showed exciting insecticidal activity against lepidopteron and other insect pests [7]. Benzophenone is used as flavor ingredient, a fragrance enhancer, a perfume fixative, and an additive for plastics coating and adhesive formulations. It is also used in the manufacture of insecticides, agricultural chemicals hypnotic drugs, antihistamines and other pharmaceuticals [8].

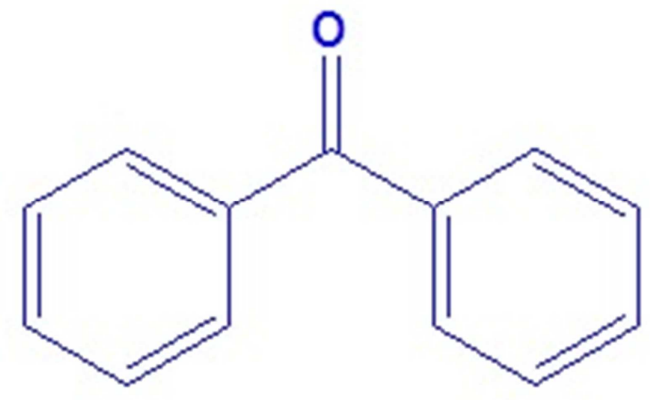

Figure 1. Structure of benzophenone

Besides its high usability as industrial chemical, it contributes to carcinogenicity due to the high reactivity and instability of benzophenone anion (benzophenone work via formation of an anion). Hence, the stability of benzophenone is important to perform controlled reduction at normal reaction conditions, which could be enhanced by Mr. Trivedi's unique biofield energy treatment, which is already known to alter the physical and structural properties of various living organisms and non-living substances [9]. The biofield is the energy fields that purportedly surround and penetrate the human body. Human has the ability to harness this form of energy from the universe and can transmit into any object around the Globe. The object(s) always receive the energy and responded into useful way. This process is known as biofield treatment. Mr. Trivedi's unique biofield treatment is also called as The Trivedi Effect $^{\circledR}$. The impact of the Trivedi Effect has been well studied in various research fields like microbiology $[9,10]$, materials sciences $[11,12]$, and agricultural research [13]. Based on the outstanding results achieved by biofield treatment on microbiology, materials sciences, and in agricultural research, an attempt was made to evaluate the effect of biofield treatment on thermal, spectroscopic and chemical properties with special interest of change in isotopic abundance ratio, $(\mathrm{PM}+1) / \mathrm{PM}$ and $(\mathrm{PM}+2) / \mathrm{PM}$ in benzophenone.

\section{Experimental}

Benzophenone was procured from Research Lab., India. The compound was distributed into two groups, where one part was referred as control and the other as treated group. The treated group in sealed pack was handed over to Mr. Trivedi for biofield treatment through his energy transmission process under standard laboratory conditions. The control and treated samples were characterized using, gas chromatography-mass spectrometry (GC-MS), high performance liquid chromatography (HPLC), differential scanning calorimetry
(DSC), Fourier transform infrared (FT-IR) spectroscopy, and ultraviolet-visible (UV-Vis) spectroscopy.

\section{1. $G C-M S$}

The gas chromatography-mass spectroscopy (GC-MS) analysis was performed on Perkin Elmer/auto system XL with Turbo mass, USA, having detection limit up to 1 picogram. For GC-MS analysis the treated sample was further divided into three parts as T1, T2, and T3. The GC-MS spectra were plotted as the $\%$ abundance $v s$. mass to charge ratio $(\mathrm{m} / \mathrm{z})$. The isotopic abundance ratio ${ }^{13} \mathrm{C} /{ }^{12} \mathrm{C}$ or ${ }^{2} \mathrm{H} /{ }^{1} \mathrm{H},(\mathrm{PM}+1) / \mathrm{PM}$, and ${ }^{18} \mathrm{O} /{ }^{16} \mathrm{O},(\mathrm{PM}+2) / \mathrm{PM}$ was expressed by its deviation in treated samples as compared to the control. The percentage change in isotopic ratio $(\mathrm{PM}+1) / \mathrm{PM}$ and $(\mathrm{PM}+2) / \mathrm{PM}$ were calculated on a percentage scale from the following formula:

$$
\begin{aligned}
& \text { Percent change in isotopic abundance ratio } \\
& \qquad=\frac{\mathrm{R}_{\text {Treated }}-\mathrm{R}_{\text {control }}}{\mathrm{R}_{\text {control }}} \times 100
\end{aligned}
$$

Where, $\mathrm{R}_{\text {Treated }}$ and $\mathrm{R}_{\text {Control }}$ are the ratio of intensity at $(\mathrm{PM}+1)$ to $\mathrm{PM}$ in mass spectra of treated and control samples, respectively.

\subsection{HPLC}

The HPLC analysis was performed on a Knauer High Performance Liquid Chromatograph (Berlin, Germany), equipped with Smartline Pump 1000 and a UV 2600 detector. Chromatographic separation was performed on a $\mathrm{C}_{18}$ column (Eurospher 100) with a dimension of $250 \times 4 \mathrm{~mm}$ and $5 \mu \mathrm{m}$ particle size. The mobile phase used was methanol with a flow rate of $1 \mathrm{~mL} / \mathrm{min}$. Temperature of the experiment was kept $\sim 25^{\circ} \mathrm{C}$. The solutions of standard and the samples were prepared in methanol. The method development for this assay of benzophenone based on its chemical properties. Benzophenone is polar molecule and, therefore, a polar solvent methanol was used as the diluent.

\section{3. $\mathrm{DSC}$}

Differential scanning calorimeter (DSC) of Perkin Elmer/Pyris-1, USA, with a heating rate of $10^{\circ} \mathrm{C} / \mathrm{min}$ and nitrogen flow of $5 \mathrm{~mL} / \mathrm{min}$ was used for thermal analysis. The change in latent heat $(\Delta \mathrm{H})$ of control and treated ethanol was recorded from their respective DSC curves.

\subsection{FT-IR}

The FT-IR spectra were obtained from Shimadzu's Fourier transform infrared spectrometer (Japan) in the frequency region of 400-4500 $\mathrm{cm}^{-1}$. FT-IR of control and treated samples of benzophenone was carried out to determine the effect of biofield energy treatment on molecular level like dipole moment, force constant, and bond strength in the compound. The samples were prepared by grinding benzophenone crystals with spectroscopic grade $\mathrm{KBr}$ into fine powder and then pressed into pellets. 


\subsection{UV-Vis Spectroscopy}

UV spectra of control and treated samples of benzophenone were acquired from Shimadzu UV-2400 PC series spectrophotometer. Quartz cell with $1 \mathrm{~cm}$ and a slit width of $2.0 \mathrm{~nm}$ were used for analysis within the wavelength region of $200-400 \mathrm{~nm}$.

\section{Results and Discussion}

\subsection{GC-MS Analysis}

The GC-MS spectra of control, and treated samples of benzophenone are presented in Figure 2. Mass spectra showed the PM peak at $\mathrm{m} / \mathrm{z}=182$ in control and all treated benzophenone samples (T1, T2, and T3) with different intensities. However, the base peak was found at $\mathrm{m} / \mathrm{z}=105$ in control, $\mathrm{T} 1$ and $\mathrm{T} 3$ samples. The intensity ratio of $(\mathrm{PM}+1) / \mathrm{PM}$ and $(\mathrm{PM}+2) / \mathrm{PM}$ are presented in Table 1 and percent change in isotopic abundance ratio was calculated and shown in Figure 3. Four major peaks at $m / z=182,105,77$, and 51 were observed in both control and treated samples of benzophenone due to the following ions respectively: $\mathrm{C}_{13} \mathrm{H}_{10} \mathrm{O}^{+}, \mathrm{C}_{7} \mathrm{H}_{5} \mathrm{O}^{+}$, $\mathrm{C}_{6} \mathrm{H}_{5}{ }^{+}$, and $\mathrm{C}_{4} \mathrm{H}_{3}{ }^{+}$ions. Peaks at $m / z=105,77$, and 51 were observed due to the fragmentation of benzophenone to benzaldehyde, phenyl and buten-3-yne ions. All peaks were same for both control and treated samples and well matched with reported literature [14].
The isotopic abundance ratio of $(\mathrm{PM}+1) / \mathrm{PM}$ of benzophenone sample was slightly increased in T1 $(5.79 \%)$ and T3 $(4.47 \%)$ and decreased significantly in T2 (-44.87\%) after biofield energy treatment. However, the isotope abundance ratio of $(\mathrm{PM}+2) / \mathrm{PM}$ was increased significantly up to $22.64 \%$ in $\mathrm{T} 3(\mathrm{~T} 1=20.84 \%, \mathrm{~T} 2=6.4 \%$,). The decreased isotopic abundance ratio of $(\mathrm{PM}+1) / \mathrm{PM}$ in treated benzophenone may decrease $\mu$ (effective mass) and binding energy in this molecule with lighter isotopes, where the increased isotope abundance ratio of $(\mathrm{PM}+2) / \mathrm{PM}$ in treated benzophenone may increase $\mu$ (effective mass) and binding energy of C-O bond. This may alter the property of the chemical bond and eventually property of the molecule. The transformation may be happened in the nuclear level due to the biofield treatment. It is expected that some of ${ }^{16} \mathrm{O}$ may be interconverted to ${ }^{18} \mathrm{O}$ atoms inside the molecule. Bond strength also plays an important role in kinetic effects due to the greater strength of the isotopic bonds such as ${ }^{2} \mathrm{H}^{12} \mathrm{C}$ bond relative to ${ }^{1} \mathrm{H}^{-12} \mathrm{C}$ bond [15].

Table 1. GC-MS isotopic abundance analysis result of benzophenone.

\begin{tabular}{lllll}
\hline Peak Intensity & Control & Treated & & \\
\hline & & T1 & T2 & T3 \\
\hline$m / z=(\mathrm{PM})$ & 98 & 95 & 100 & 82.19 \\
$m / z=(\mathrm{PM}+1)$ & 23.11 & 23.76 & 13 & 20.25 \\
$m / z=(\mathrm{PM}+2)$ & 1.75 & 2.05 & 1.9 & 1.8 \\
\hline
\end{tabular}

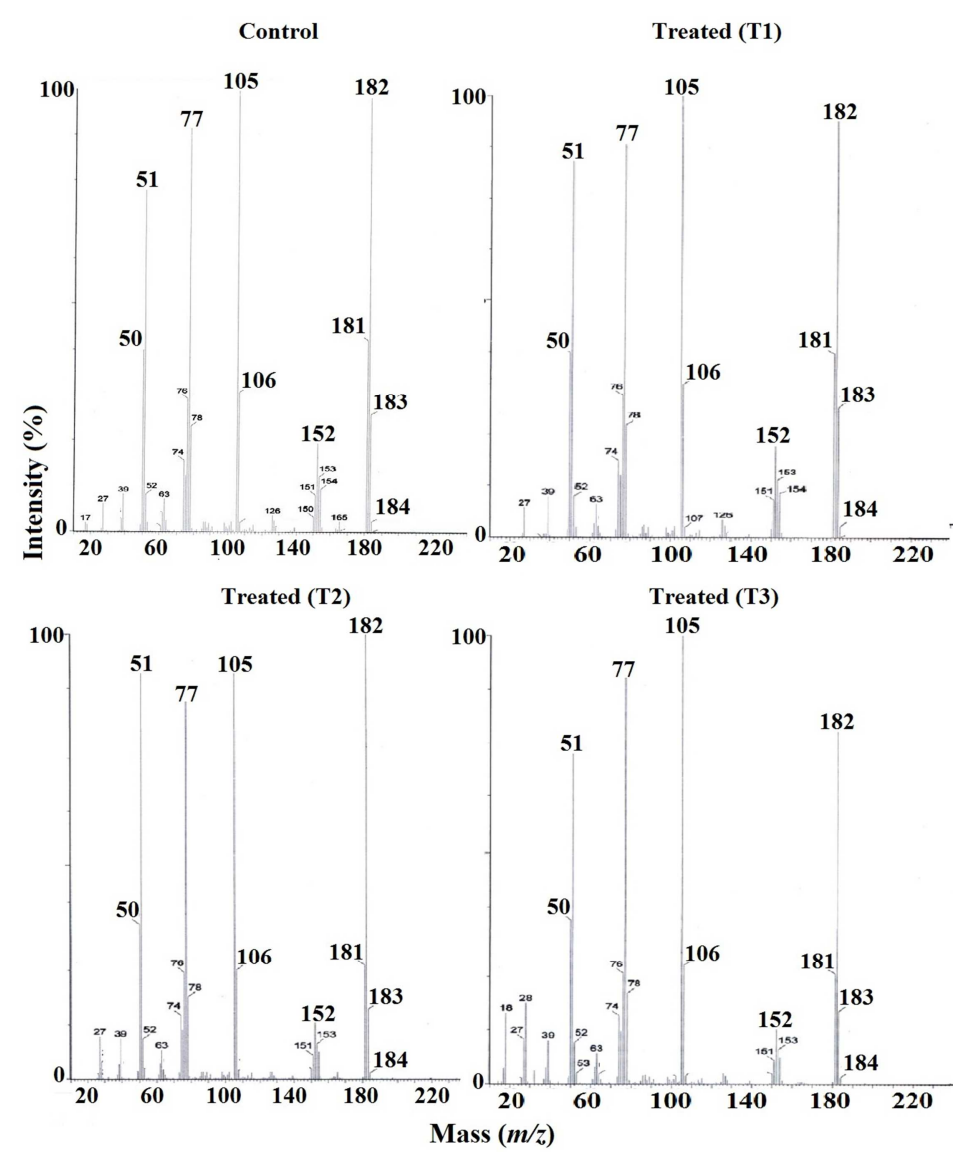

Figure 2. GC-MS spectra of control and treated benzophenone sample. 


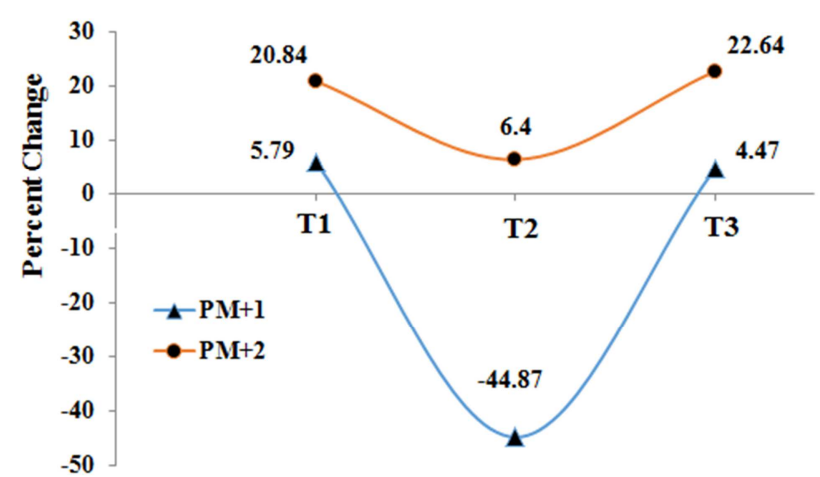

Figure 3. Percent change in isotopic abundance $(P M+1) / P M$ and $(P M+2) / P M$ of benzophenone under biofield treatment as compared to control.

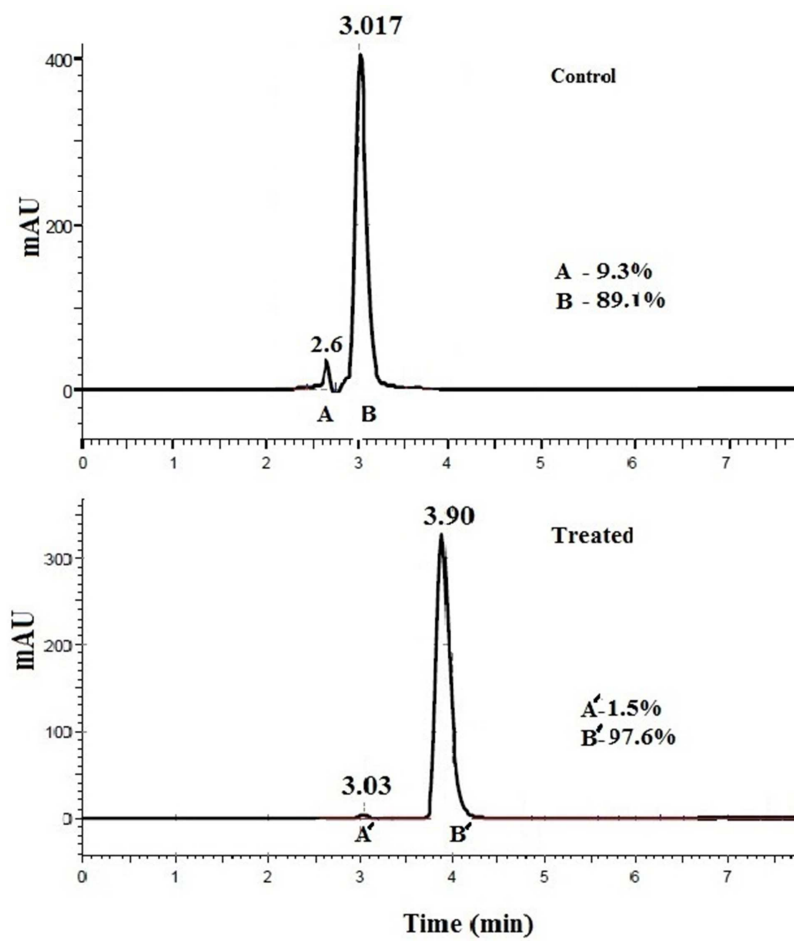

Figure 4. HPLC chromatogram of control and treated benzophenone.

\subsection{HPLC Analysis}

HPLC chromatogram of control and treated benzophenone is shown in Figure 4. The compounds have been separated into two peaks in both control and treated samples. The retention time $\left(\mathrm{T}_{\mathrm{R}}\right)$ of control benzophenone sample showed at $3.02 \mathrm{~min}$ with $89.1 \%$ relative intensity and another small peak at 2.6 min of $9.3 \%$ intensity, however after biofield treatment, this highly intense peak was shifted to 3.90 min with $97.6 \%$ intensity and the small peak at 3.03 min with $1.5 \%$ intensity. This increased $T_{R}$ may be attributed to the decreased polarity of benzophenone after biofield energy treatment. Further, the decreased polarity after biofield treatment may be due to change in planarity of the two benzene ring that resulted into higher $\mathrm{T}_{\mathrm{R}}[2,16,17]$.

\subsection{DSC Analysis}

DSC was used for thermal analysis of control and treated benzophenone samples. The change in heat $(\Delta \mathrm{H})$ of control and treated samples is presented in Table 2. It showed one strong endothermic transition at $208.01^{\circ} \mathrm{C}$, however the endothermic transition was observed at $192.55^{\circ} \mathrm{C}$ after biofield energy treatment. The heat absorbed $(\Delta \mathrm{H})$ was increased from 65.33 $\mathrm{J} / \mathrm{g}$ (control) to $505.76 \mathrm{~J} / \mathrm{g}$ in treated benzophenone sample. The increase in $\Delta \mathrm{H}$ in the treated sample was significantly increased by $674.16 \%$ as compared to the control. The increase in $\Delta \mathrm{H}$ after biofield treatment could be due to alteration of intermolecular interaction (van der Waals interactions) in benzophenone crystal that might increase the thermal stability of the treated samples [16].

Table 2. DSC analysis of benzophenone.

\begin{tabular}{lll}
\hline & Peak position $\left({ }^{\circ} \mathbf{C}\right)$ & $\Delta \mathbf{H}(\mathbf{J} / \mathbf{g})$ \\
\hline Control & 208.01 & -65.33 \\
Treated & 192.55 & -505.76 \\
Percent change & -7.43 & 674.16 \\
\hline
\end{tabular}

\subsection{FT-IR Spectroscopic Analysis}

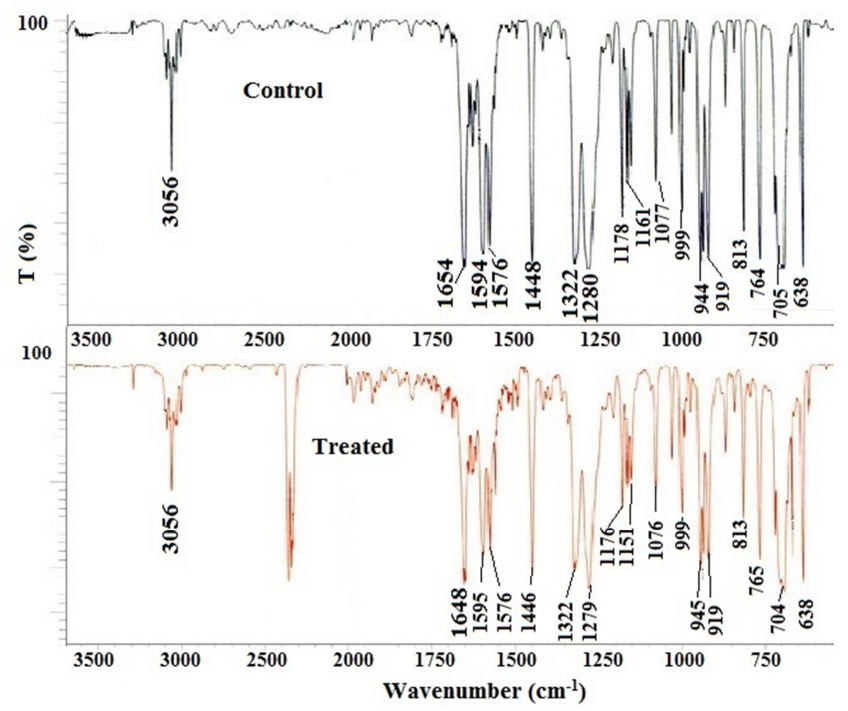

Figure 5. FT-IR spectra of control and treated benzophenone.

The FT-IR spectrum of control and biofield energy treated benzophenone is showed in Figure 5. The vibrational peak at $3056 \mathrm{~cm}^{-1}$ was assigned to aromatic $\mathrm{C}-\mathrm{H}$ stretching of the phenyl ring. The vibrational peak at $1654 \mathrm{~cm}^{-1}$ in control sample was assigned to $\mathrm{C}=\mathrm{O}$ stretching vibration, that was shifted by $6 \mathrm{~cm}^{-1}$ to $1648 \mathrm{~cm}^{-1}$ after biofield energy treatment. This result was well supported by isotopic abundance ratio calculated from GC-MS. Due to the increased isotopic abundance ratio of ${ }^{18} \mathrm{O} /{ }^{16} \mathrm{O}$ in treated benzophenone, the effective mass $(\mu)$ increased and finally wavenumber decreased. The $\mathrm{C}-\mathrm{H}$ in-plane bending vibrations were observed at $\sim 1178 \mathrm{~cm}^{-1}$ and $1161 \mathrm{~cm}^{-1}$ in control and $1176 \mathrm{~cm}^{-1}$ and $1151 \mathrm{~cm}^{-1}$ in treated sample. The peaks observed between 
$1594 \mathrm{~cm}^{-1}$, and $1576 \mathrm{~cm}^{-1}$ in control and treated samples have been assigned to $\mathrm{C}-\mathrm{C}$ stretching vibrations in aromatic ring. The FT-IR results after biofield treatment as compared to the control, have shown little changes in structural properties of the molecule except the $\mathrm{C}=\mathrm{O}$ stretching frequencies, which lead to the changes in planarity and polarity of benzophenone crystal.

\subsection{UV-Vis Spectroscopic Analysis}

The UV spectra of control and treated samples of benzophenone are shown in Figure 6. The UV spectrum of control sample showed characteristic absorption peaks at $\lambda_{\max }=210 \mathrm{~nm}$ and $257 \mathrm{~nm}$. However, the biofield treated sample showed characteristic absorption peaks at, $205 \mathrm{~nm}$ and $252 \mathrm{~nm}$. Reported literature have suggested that the first strong band in the region of $240-300 \mathrm{~nm}$ corresponds to $\pi-\pi^{*}$ transitions and the weak $n-\pi^{*}$ band in the region of $320-370$ $\mathrm{nm}$ [17]. In this UV-Vis spectra we have not observed any characteristics absorption peak in the region of 320-370 nm. This may be due to the weaker intensity of the $n-\pi^{*}$ band to observe in such a low concentration. The $\pi-\pi^{*}$ and $n-\pi^{*}$ bands show large and distinct shift with the polarity of the medium/solvent. Hence, it is hypothesized that biofield treatment might induced nonpolarity to the system that makes shift of the absorption positions. The $\pi-\pi^{*}$ band suffers a blue shift of around $5 \mathrm{~nm}$ which is indicative of the fact that there may be decreases in polarity of the molecule [17]. This observation is also supported by the higher $\mathrm{T}_{\mathrm{R}}$ of the treated sample in HPLC chromatogram.

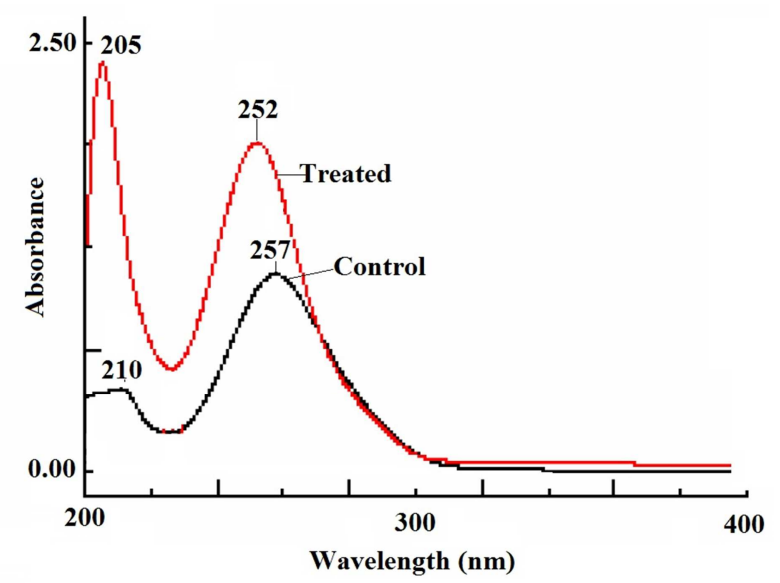

Figure 6. UV-Vis spectra of control and treated samples of benzophenone.

\section{Conclusions}

Benzophenone was studied to see the effect of biofield treatment and compared for their isotope abundance ratio with the control one. GC-MS data showed that the isotopic abundance ratio of (PM+1)/PM was decreased to $44.87 \%$ and $(\mathrm{PM}+2) / \mathrm{PM}$ was increased from $6.4 \%$ to $22.64 \%$ in treated sample as compared to the control. Biofield may also alter the planarity of the molecule which eventually alter the polarity and showed higher retention time $\left(T_{R}\right)$ in HPLC chromatogram. As a result a hypsochromic shift was observed in characteristic absorption position in UV-Vis spectra. Higher isotopic ratio $(\mathrm{PM}+2) / \mathrm{PM}$ may be the reason for higher energy change in DSC study as compared to the untreated samples. It is assumed that biofield energy treatment may enhance the number of heavier ${ }^{18} \mathrm{O}$ isotope in treated benzophenone that might be shifted the $\mathrm{C}=\mathrm{O}$ stretching frequency towards lower energy region by increasing effective mass $(\mu)$. Thereby, the stability might increase in the organic small molecules of industrial importance by means of increasing effective mass $(\mu)$, which ultimately affect the shelf-life and efficacy of the final product.

\section{Acknowledgements}

The authors would like to acknowledge the whole team of Sophisticated Analytical Instrument Facility (SAIF), Nagpur for providing the instrumental facility. We are very grateful for the support of Trivedi Science, Trivedi Master Wellness and Trivedi Testimonials in this research work.

\section{References}

[1] HSDB (2010). Benzophenone. Hazardous substance database. http://toxnet.nlm.nih.gov/.

[2] Khemiri, N., Messaoudi, S., Abderrabba, M., Spighi, G., Gaveau, M.A., Briant, M. et al. (2015) Photoionization of benzophenone in the gas phase: Theory and experiment. J Phys Chem A 119: 6148-6154.

[3] Kanerva, L., Elsner, P., Wahlberg, J.E. and Maibach, H.I. (2012) Handbook of occupational dermatology. Springer, Berlin.

[4] Zucchi, S., Bluthgen, N., Ieronimo, A. and Fent, K. (2011) The UV-absorber benzophenone-4 alters transcripts of genes involved in hormonal pathways in zebrafish (Danio rerio) eleuthero-embryos and adult males. Toxicol Appl Pharmacol 250: $137-146$

[5] Carroll, G.T., Turro, N.J. and Koberstein, J.T. (2010) Patterning dewetting in thin polymer films by spatially directed photo crosslinking. J Colloid Interface Sci 351: 556-560.

[6] Scientific Opinion of EFSA prepared by the Panel on food contact materials, enzymes, flavourings and processing aids (CEF) on Toxicological evaluation of benzophenone. The EFSA Journal (2009) 1104, 1-30.

[7] Li, W.Q., Zhang, Z.J., Nan, X., Liu, Y.Q., Hu, G.F., Yu, H.T. et al. (2014) Design, synthesis and bioactivity evaluation of novel benzophenone hydrazone derivatives. Pest Manag Sci 70: 667-673.

[8] HSDB Benzophenone (2013) Hazardous substance database, http://toxnet.nlm.nih.gov/.

[9] Trivedi, M.K., Patil, S., Shettigar, H., Bairwa, K. and Jana, S. (2015) Phenotypic and biotypic characterization of Klebsiella oxytoca: An impact of biofield treatment. J Microb Biochem Technol 7: 203-206.

[10] Trivedi, M.K., Patil, S., Shettigar, H., Gangwar, M. and Jana, S. (2015) Antimicrobial sensitivity pattern of Pseudomonas fluorescens after biofield treatment. J Infect Dis Ther 3: 222. 
[11] Trivedi, M.K., Tallapragada, R.M., Branton, A., Trivedi, D., Nayak, G. Latiyal, O. et al. (2015) Potential impact of biofield treatment on atomic and physical characteristics of magnesium. Vitam Miner 3: 129.

[12] Trivedi, M.K., Nayak, G., Patil, S., Tallapragada, R.M., Latiyal, O. and Jana, S. (2015) An evaluation of biofield treatment on thermal, physical and structural properties of cadmium powder. J Thermodyn Catal 6: 147.

[13] Shinde, V., Sances, F., Patil, S. and Spence, A. (2012) Impact of biofield treatment on growth and yield of lettuce and tomato. Aust J Basic \& Appl Sci 6: 100-105.

[14] http://webbook.nist.gov/cgi/cbook.cgi?ID=C119619\&Mask=2 00\#Mass-Spec.
[15] Rieley, G. (1994) Derivatization of organic-compounds prior to gas-chromatographic combustion-isotope ratio mass-spectrometric analysis: Identification of isotope fractionation processes. Analyst 119: 915-919.

[16] Fleischer, E.B., Sung, N. and Hawkinson, S. (1968) Crystal structure of benzophenone. J Phys Chem 72: 4311-4312.

[17] Georg, H.C., Coutinho, K. and Canuto, S. (2007) Solvent effects on the UV-visible absorption spectrum of benzophenone in water: A combined Monte Carlo quantum mechanics study including solute polarization. J Chem Phys 126: 034507 (1-8). 